\title{
Marcuse: \\ Uma Leitura Reducionista da Obra Freudiana
}

CARLOS ALBERTO PLASTINO*

\section{RESUMO}

$O$ artigo discute a leitura da obra freudiana realizada por Marcuse, assinalando que a interpretação desse autor reduz a significação dos conceitos freudianos de princípio de prazer e princípio de realidade no contexto de uma compreensão caracterizada pela centralidade do trabalho na produção das subjetividades. Na perspectiva de Marcuse, essa leitura reducionista ignora a significação da virada teórica empreendida por Freud desde 1920, produzindo, assim, uma segunda redução dos conceitos freudianos, na medida em que a segunda teoria pulsional é interpretada ao contexto dos conceitos "princípio de prazer" e "princípio de realidade". Como consequiência desse duplo reducionismo - diferentemente de Freud - Marcuse desconsidera a significação da lei na construção da democracia.

Palavras-chave: Reducionismo; princípio de prazer; princípio de realidade; psicanálise; complexidade.

\section{ABSTRACT}

\section{Marcuse: A Reductionist Reading of Freud's Works}

The article discusses Marcuse's reading of Freud's works, pointing out that his interpretation reduces the meaning of Freudian concepts of pleasure principle and reality principle in the context of an understanding characterized by the centrality of work in the production of subjectivities. In Marcuse's

* Psicanalista, cientista político, professor do Instituto de Medicina Social da Universidade do Estado do Rio de Janeiro e da Pontifícia Universidade Católica do Rio de Janeiro. 
perspective. this reductionist reading overlooks the significance of Freud's theoretical turn from 1920 on, thus producing a second reduction of the Freudian concepts, insofar as the second instinctual theory is interpreted within the "pleasure principle" and "reality principle" concepts. As a consequence of such a double reductionism - differently from Freud Marcuse does not take into consideration the significance of law in the construction of democracy.

Keywords: Reductionism; pleasure principle; reality principle; psychoanalysis; complexity.

\section{RÉSUMÉ}

\section{Marcuse: Une Lecture Réductionniste de l'Oeuvre Freudienne}

L'article discute la lecture de l'oeuvre freudienne fait par Marcuse, remarquant que l'interpretation de cet auteur-là réduit la signification des concepts freudiens du principe de plaisir et du principe de réalité dans le contexte d'une compréhension caracterisée par la centralité du travail dans la production des subjectivités. Dans la perspective de Marcuse, cette lecture réductionniste ignore la signification du virage théorique entreprit par Freud après 1920, ainsi produisant une deuxième réduction des concepts freudiens fondamentaux à mesure que la deuxième théorie pulsionelle est interpretée selon les concepts "principe de plaisir" et "principe de réalité". En conséquence de ce double réductionnisme - différemment de Freud - Marcuse ignore la signification de la loi dans la construction de la démocratie.

Mots-clé: Réductionnisme; principe de plaisir; principe de réalité; psychanalyse; complexité.

Recebido em 22/6/98.

Aprovado em 5/8/98. 
A obra de Herbert Marcuse representou uma importante contribuição ao pensamento crítico do pós-guerra. Tendo como interlocutor privilegiado ao marxismo clássico, criticava-lhe a incapacidade de integrar o "fator subjetivo" na sua concepção de homem, e, portanto, na de sujeito revolucionário. Não estava sozinho nessa crítica. Boa parte do trabalho inicialmente desenvolvido pela Escola de Frankfurt foi inspirada por uma preocupação similar, isto é, pela necessidade de repensar a teoria social visando a compreender a impotência da teoria marxista face aos processos sociais que levaram ao estabelecimento do fascismo e, posteriormente, à segunda guerra mundial. O marxismo clássico sempre pensou a questão do sujeito revolucionário ao interior da perspectiva do Iluminismo. Tratava-se de formar a consciência autônoma do proletariado no bojo de um processo onde a expansão da racionalidade faria recuar a alienação dos sujeitos sociais. Essa redução do sujeito à consciência deixou o marxismo totalmente desarmado para compreender as fortíssimas motivações irracionais que atravessaram os processos de pré-guerra. Marcuse tentou superar essa limitação acrescentando a seu quadro teórico a perspectiva do inconsciente e da vida pulsional, cerne da descoberta freudiana. Esses conceitos, interpretados como se verá de maneira muito singular por Marcuse, eram minimizados ou mesmo negados pelo grupo que ele denomina "neofreudiano". Esse grupo foi um segundo e importante interlocutor.

O fracasso teórico do marxismo constituiu, assim, uma forte motivação para a revisão teórica empreendida por Marcuse, mas não foi a única. Também as mudanças verificadas na dinâmica do sistema capitalista pareciam exigir dita revisão. Com efeito, o prolongado e extraordinário processo de crescimento de pós-guerra indicava, para muitos, que a etapa das crises econômicas periódicas tinha concluído, e com ela a pertinência de pensar o sujeito revolucionário nos moldes do marxismo clássico. Mas se o desenvolvimento e a estabilidade do capitalismo tinham conseguido integrar a classe operária, desmontando seu potencial revolucionário, o contexto geral da dominação capitalista, em particular a limitação dos espaços de liberdade que ela acarretava, parecia ter criado novos espaços de luta e de emergência de novos sujeitos de transformação social. Como se verá, essa questão é abordada por Marcuse privilegiando as relações entre o princípio de prazer e o princípio de realidade, dos quais ele faz uma interpretação singular.

A releitura de sua obra Eros e civilização, quase cinqüenta anos após sua publicação, constitui uma experiência instigante. Essa obra - quiçá a mais conhecida de Marcuse - teve, como se sabe, forte influência na concepção 
do mundo que inspirou o multifacetado movimento sociocultural designado como "contracultura". O esgotamento desse movimento, e sua posterior caracterização como utopia irrealizável, não deve ofuscar sua contraditória influência na evolução cultural contemporânea. Embora para a leitura atual a obra de Marcuse ressoe como um pensamento ultrapassado, muitas das preocupações que a inspiraram continuam atuais. Por outro lado, a leitura de sua obra nos permite acompanhar os debates da época de sua elaboração, mostrando a formulação de um "pensamento otimista, mesmo positivo", no dizer do próprio Marcuse ("Prefácio político" a Eros e civilização, op. cit., 1966; e 1986: 13). Dito otimismo parecia justificado na época pelo próprio desenvolvimento do capitalismo, num momento em que "a conquista da natureza está praticamente concluída e mais necessidades de um maior número de pessoas são satisfeitas numa escala nunca anteriormente vista" (cf. Marcuse, Eros e civilização, op. cit., 1986: 27). E ainda pela análise das tendências que permitiam antecipar o que, logo a seguir, seriam as diversas manifestações do que parecia ser um multifacetado - da insurgência de países do terceiro mundo à contracultura nos países centrais - movimento contestatório do capitalismo imperialista. $\mathrm{O}$ evidente contraste existente entre dito otimismo e a ampla hegemonia da ideologia neoliberal hoje vigente, impõe a revisão dos pressupostos teóricos que sustentaram a leitura marcusiana, aprofundando a crítica teórica por ele desenvolvida através da incorporação de questões ausentes naqueles debates, e que remetem, num nível de maior profundidade, às concepções fundamentais do paradigma da modernidade. Esse empreendimento se torna necessário já que, embora alguns dos fatores que impulsionaram a crise desse paradigma existam pelo menos desde os primeiros anos deste século, sua integração na reflexão contemporânea nas diversas áreas do conhecimento e, sobretudo, suas conseqüências sobre os pressupostos ontológicos, epistemológicos e antropológicos destas, se consolidaram a partir da década dos anos setenta, encontrando-se hoje em pleno processo de desenvolvimento.

A resistência do paradigma da modernidade, ainda vigente na reflexão contemporânea, orientou uma leitura e uma interpretação reducionista da psicanálise freudiana, escamoteando assim sua contribuição - na sua elaboração madura - para a crítica radical daquele paradigma. A leitura marcusiana da obra freudiana me parece constituir um exemplo desse tipo de interpretação reducionista. Ela enfraquece o impacto teórico das descobertas freudianas e acaba por esterilizar o esforço que desenvolve no sentido de utilizar o instrumental teórico psicanalítico para incorporar uma nova 
perspectiva antropológica na compreensão dos processos sociais. As consideraçōes que seguem serão dedicadas à discussão dessa problemática.

\section{Repressão e Civilização}

A proposição freudiana segundo a qual a civilização se baseia na subjugação das pulsões humanas, processo esse considerado por Freud "inevitável e irreversível", constitui o alvo da crítica marcusiana. Necessário para a constituição da vida civilizada, esse processo repressivo teria se tornado - na perspectiva de Marcuse - superável como conseqüência dos desenvolvimentos que ele próprio fez possível. Assim sendo, a conclusão de Freud segundo a qual "a felicidade não é um valor cultural" deveria ser criticada e revista no estágio atual de evolução da humanidade (cf. Marcuse, Eros e civilizaçāo, op. cit., 1986). Essa leitura marcusiana sustenta-se, a meu ver, numa interpretação singular - e reducionista - dos conceitos freudianos de princípio de prazer e princípio de realidade; interpretação essa estreitamente ligada à teorização marxista e à centralidade do trabalho nessa teoria. É interessante sublinhar, incidentalmente, que a tese marcusiana da superabilidade da repressão é paralela à tese marxista sobre a superabilidade da formação social capitalista. Segundo essa tese, o capitalismo teria constituído um momento necessário da história humana, na medida em que fez possível a acumulação de capital e o desenvolvimento das forças produtivas; entretanto, o seu próprio desenvolvimento tornaria possível e necessária a sua superação, liberando a humanidade do reino da necessidade e inaugurando a história verdadeiramente humana. Analogamente, a repressão das pulsões teria sido necessária para a constituição e desenvolvimento da civilização mas, pela própria evolução das forças produtivas e a liberação da necessidade de orientar a energia libidinal para a reprodução material, dita repressão teria se tornado desnecessária e superável. Nos dois casos, a transformação teria como pressuposto o desenvolvimento das forças produtivas e a liberação da necessidade de trabalhar. Essa concepção parece-me tributária da perspectiva teórica que postula para a história um percurso necessário; percurso esse oculto pelas "astúcias da razão", operando conforme a dialética da contradição e da superação da contradição. A inserçāo dessa perspectiva na concepção da ontologia da modernidade parece-me evidente.

Afirmei acima que a compreensão marcusiana dos conceitos freudianos de princípio de prazer e de realidade era reducionista, na medida em que a 
necessidade de adiar a satisfação imediata era pensada apenas como conseqüência da necessidade do trabalho como condição de sobrevivência. Nessa ótica, o princípio de realidade é assimilado ao "princípio de desempenho", entendendo por tal "o conjunto de instituições e relações que constituem o corpo social do princípio de realidade", destacando o fato de que, "sob seu domínio, a sociedade é estratificada de acordo com os desempenhos econômicos concorrentes de seus membros" (idem: 57-58). É verdade que no mesmo texto citado Marcuse afirma não ser o princípio de desempenho o único princípio histórico de realidade, mas as manifestações do princípio de realidade que ele parece considerar apontam sempre para estruturas sociais de dominação, desdenhando o que, para Freud, constituía "um bloco de natureza invencível, na nossa própria organização psíquica" (cf. Freud, "El malestar en la cultura", 1976: 85).

Parece-me indiscutível que o princípio de realidade adquire, em cada formação social, modalidades específicas. Entretanto, esse fato não anula, na concepção freudiana, seu caráter constitutivo em toda forma de vida social. A distinção estabelecida por Marcuse entre repressão e mais-repressão parece, em certos momentos de seu discurso, apontar para o reconhecimento desse fato, constituindo a "mais-repressão" os "controles adicionais acima e além dos indispensáveis à associação civilizada humana" (Marcuse, Eros e civilização, op. cit., 1986: 53). Entretanto, essa imprescindível diferenciação acaba sendo ignorada por Marcuse, que chega a afirmar que a repressão é, substancialmente, mais-repressão (idem: 143). Assim, é a redução do princípio de realidade ao princípio de desempenho que permite a Marcuse criticar a concepção freudiana sobre a inevitabilidade da repressão das pulsões como base da civilização. O argumento de Freud é falacioso - afirma - já que a carência na realidade é conseqüência de uma organização específica (ibidem: 51), e sendo a carência a que torna necessária a repressão das pulsões, esta não seria inevitável em qualquer forma de organização social mas apenas naquelas que impõem a carência.

Entretanto, na perspectiva freudiana a necessidade de transformar o princípio de prazer pela mediação do princípio de realidade é pensada certamente no contexto da necessidade de reproduzir - pelo trabalho - a vida material. Esse nāo é, porém, o motivo exclusivo que fundamenta a necessidade do princípio de realidade. De maneira muito mais ampla a imposição desse princípio visa à constituição do indivíduo como ser social, o que se supõe levar em conta os constrangimentos impostos pela realidade efetiva; inclui nessa realidade a ineliminável relaçāo com o Outro, relação ancorada no 
desamparo humano e na vida pulsional. Para Freud, não é apenas a Ananké que é preciso atribuir a paternidade da civilização, mas aos esforços combinados de Eros e Ananké, sendo que o papel protagônico nesse processo deve ser atribuído a Eros (cf. Freud, "El malestar en la cultura", op. cit.). $\mathrm{Na}$ concepção freudiana madura, Eros divide com a pulsão de morte o governo do processo vital, e é precisamente a principal manifestação desta última, a pulsão destrutiva, que torna necessária e irreversível certo grau de repressão pulsional. Referindo-se à tese "dos comunistas" (idem: 111ss), segundo a qual a supressão da propriedade privada eliminaria a agressividade entre os homens, Freud critica como uma "vã ilusão" o que considera a premissa psicológica dessa tese. Afirma que a eliminação da propriedade privada suprimiria um dos motivos da agressão, poderoso sem dúvidas, porém não o mais poderoso. É que a agressão, continua dizendo, não foi criada pela instituição da propriedade, reinou quase sem limites em época primordiais, e é constatável nas crianças, quando a propriedade ainda não abandonou sua forma anal primordial. A agressão, conclui Freud, "constitui o pano de fundo de todos os vínculos de amor entre os seres humanos" (ibidem: 110).

A leitura marcusiana do conceito freudiano de princípio de realidade parece-me ser reducionista na medida em que Marcuse a reduz ao âmbito da lida com a natureza através do trabalho, ignorando seu papel central nas relações com os outros e minimizando o papel fundamental da pulsão agressiva, ignorando assim o que Freud considera, como foi mencionado acima, "um bloco da natureza invencível na nossa própria organização psíquica". Esse reducionismo da leitura marcusiana da obra de Freud se sustenta ainda numa deficiente compreensão do processo de elaboração dos conceitos freudianos e em conseqüência de seu sentido. Com efeito, os conceitos "princípio de prazer" e "princípio de realidade" foram cunhados por Freud num momento relativamente inicial de sua obra teórica, sendo inequivocamente tributários - em sua elaboração metapsicológica - do fisicalismo então dominante. Todavia, esses conceitos foram permanentemente reelaborados por Freud, devendo ser interpretados ao contexto da elaboração final da teoria freudiana, hegemonizada pela segunda teoria pulsional, pela ambivalência afetiva originária e pelo desamparo. Tomados de Fechner, esses conceitos tiveram - no dizer de Octave Mannoni (1977) - um papel capital, mas posteriormente não conduziram a novos desenvolvimentos. É verdade que Freud continuou a se utilizar desses conceitos até o final de sua obra, mas também os submeteu à severa crítica, indicando sua necessidade 
de repensá-los no contexto da segunda teoria pulsional, e visando a ultrapassar, essencialmente, seu aspecto quantitativo para integrar seus aspectos qualitativos (cf. Freud, "El problema económico del masoquismo", 1976: 165-167). Marcuse minimiza a significação da segunda teoria pulsional interpretando-a no contexto inicial da teorização freudiana, ela própria reinterpretada por ele de maneira reducionista. A meu ver, essa opção está estreitamente vinculada à rígida separação que Marcuse estabelece entre clínica e "filosofia" freudiana, à sua compreensão da significação da metapsicologia, e, finalmente, à sua interpretação cientificista da obra de Freud.

\section{Otimismo, Pessimismo e Democracia}

O pensamento freudiano tem sido caracterizado como pessimista. Essa caracterização é correta quando comparada com o otimismo iluminista, porém inadequada se com ela pretende-se ler nas teses de Freud a exclusão das possibilidades de transformação dos indivíduos e da sociedade. $O$ otimismo iluminista se sustentava na unilateralidade de sua concepção antropológica, centrada na racionalidade. Combinando sua concepção ontológica que pensava o real como dotado de uma racionalidade intrínseca organizada por rigorosas leis de determinação, com sua concepção antropológica que, de um lado, atribuía ao homem a capacidade potencial de apreender através de sua razão a totalidade das determinações do real, e, de outro, ignorava a imaginação e os afetos, o pensamento iluminista produziu o mito do progresso necessário. São essas concepções ontológicas, epistemológicas e antropológicas que fundamentam a compreensão da ciência como espelho da verdade do real. O teleologismo implícito nessa concepção é evidente, caracterizando inclusive as correntes de pensamento que, como o marxismo, assumiram ao interior do pensamento da modernidade uma função crítica. Também para Marx o progresso resultaria da extensão da racionalidade na vida social, mas essa extensão requeria a eliminação da alienação, ela própria resultante da divisão da sociedade em classes e da dominação que acompanha essa divisão. A superação do capitalismo - e com ela a das sociedades classistas - inauguraria a história verdadeiramente humana, marcada pela ausência de dominação e de conflito, podendo-se então prescindir do Estado à medida que a administração dos homens - própria de uma sociedade classista (cf. Freud, "Más allá del principio de placer", 1976: 42; e "El malestar en la cultura", op. cit.: 95) - seria substituída na 
sociedade comunista pela administração das coisas. Pensando o comunismo como uma necessidade histórica - e não prática ${ }^{1}$ - o marxismo se inscreveu, assim, na concepção teleológica do lluminismo, negando as intuições iniciais de Marx (cf. Marx e Engels, A ideologia alemã, 1977; e "Teses contra Feuerbach", 1974 [1845]: 55-59).

Contrastando com o otimismo iluminista, Freud não acreditava na existência de um movimento necessário que impulsionaria o progresso. Não admitia - em seu quadro conceitual - uma "pulsão de aperfeiçoamento", e não poderia fazê-lo na medida em que na sua concepção antropológica atribuía um papel fundamental à ambivalência afetiva originária. Entretanto, isto não significa negar as possibilidades de progresso da humanidade no sentido de atingir formas de convivência social caracterizadas por valores solidários e de respeito pela vida e pela diferença. O pessimismo freudiano se refere à impossibilidade de superar definitivamente os conflitos entre os homens (cf. Freud, "El malestar en la cultura", op. cit.: 109-110), porém não rejeita - antes afirma como possível e necessário - a administração democrática desses conflitos. Freud pensa a cultura como "tentativa de regular os vínculos sociais" (idem: 93), regulação cujo objetivo foi o de substituir a arbitrariedade dos indivíduos - que agiriam no sentido de seus interesses e moçōes pulsionais - pela lei. Assim o poder da comunidade se contraporia - como "direito" - ao poder do indivíduo, que passa a ser condenado como manifestação de "força bruta". Essa substituição do poder do indivíduo pelo poder da comunidade é o movimento cultural decisivo, consistindo essencialmente em que os membros da comunidade se limitam nas suas possibilidades de satisfação, enquanto o indivíduo não conhecia dita limitação. Entretanto, a introdução da lei e do direito não deve ser confundida com o estabelecimento da justiça e da democracia. Freud afirma explicitamente que a evolução da cultura exige um movimento permanente no sentido de fazer com que o direito deixe de ser expressão da vontade de uma comunidade restringida que continuaria comportando-se, com respeito às massas da população, como o faria o indivíduo violento. $\mathrm{O}$ resultado

\footnotetext{
I A necessidade histórica resulta das "astúcias da razão" e independe, em última instância, da vontade dos homens. A necessidade prática não alude a um processo que se verificará necessariamente. mas a um processo imprescindível com vistas na realização de determinados valores (justiça, fraternidade, paz), ou mesmo com vistas na sobrevivência da vida civilizada. A riqueza do pensamento marxista. que como toda obra monumental não está isenta de contradições, exigiria um tratamento mais detalhado destas questōes, tratamento que não é possível desenvolver aqui.
} 
procurado deveria ser - conclui Freud - a formulação de um direito ao que todos tenham contribuído com o sacrifício de suas pulsões e no qual ninguém seja vítima da violência bruta (ibidem: capítulo III; e, também, “¿Por qué la guerra?”, 1976: 189ss).

O pensamento freudiano sobre a vida social, o conflito e a democracia se sustenta, como afirmei, na sua concepção antropológica centrada na ambivalência afetiva originária. É em torno dessa que Freud constrói o mito narrado em "Totem e tabu", sendo à ação conjugada dos dois afetos originários que atribui primeiro o parricídio e posteriormente a introdução da lei e com ela a introdução do direito, da moral e da religião (cf. Freud, "Toten y tabú”, op. cit., 1976). Marcuse parece nāo ter compreendido a significação desse mito na obra freudiana. Com efeito, assimilando a violência do pai primevo com o princípio de realidade, afirma que o crime contra este (contra o princípio de realidade) é redimido pelo crime contra o princípio de prazer, anulando aquele. $\mathrm{Na}$ sua compreensão, o sentimento de culpa se origina na ausência de liberação do princípio de prazer (Marcuse, Eros $e$ civilização, op. cit., 1986: 75-76). Entretanto, na ótica freudiana o sentimento de culpa se origina na conservação inconsciente da moção agressiva conhecida pelo superego - e não na limitação do prazer. Freud sustenta explicitamente essa tese, opondo-se inclusive a alguns de seus mais importantes discípulos (cf. Freud, "El malestar en la cultura", op. cit.: 134, e nota 5), que atribuíam a emergência do sentimento de culpa tanto ao recalque da pulsão agressiva quanto da pulsão erótica. O estabelecimento da lei supōe, para Freud, muito mais que a restauração da limitação da satisfação pulsional. Essa limitação não pode equiparar-se à imposta pela violência arbitrária do pai primevo, na medida em que ela deriva não da vontade particular e ilimitada de um homem, mas da lei, isto é, da vontade da comunidade. Nesse sentido, poder-se-ia dizer que o mito narrado em "Totem e tabu" contém não apenas a origem da lei, da moral e da religião, mas também a origem da democracia na medida em que esta é, conforme a definição clássica, o governo da lei e não dos homens.

Certamente o mito narrado em "Totem e tabu", assim como a compreensão do drama edípico no psiquismo individual, se insere numa organização social patriarcal. Essa organização social não é obviamente a única possível. Entretanto, quaisquer que sejam as formas sociais de organização, na ótica freudiana a convivência civilizada requer da limitação pulsional e a lei na medida em que supõe a aceitação da alteridade. Todavia, é importante assinalar que essa necessidade se reduz, no pensamento freudiano, à impres- 
cindível limitação da pulsão agressiva e da pulsão erótica incestuosa, o que de modo algum pode ser interpretado como justificação, seja da exploração de classes ou de grupos, seja a imposição da monogamia ou a condenação de práticas eróticas diversas da genitalidade heterossexual. Esse aspecto é tão evidente na obra de Freud ("El malestar en la cultura", op. cit.), que me parece desnecessário insistir na sua consideração. A incompreensão por Marcuse desse aspecto central do pensamento freudiano parece-me estreitamente vinculada à sua compreensão da metapsicologia como filosofia, e em conseqüência ao desconhecimento da singularidade do processo de formulação do saber psicanalítico.

\section{Filosofia e Metapsicologia}

"A finalidade do presente ensaio", afirma Marcuse na Introdução a Eros $e$ civilização, "é contribuir para a filosofia da psicanálise, não para a psicanálise em si" (op. cit:: 30). No Epílogo de seu trabalho, dedicado à crítica do "revisionismo neofreudiano" (idem: 210), Marcuse retoma a distinção, afirmando que sua crítica se dirige à teoria psicanalítica e não aos méritos terapêuticos das escolas revisionistas, acrescentando que essa limitação é imposta não apenas pela sua própria falta de competência, mas também pela discrepância entre teoria e terapia "inerente à própria psicanálise". Esses esclarecimentos de Marcuse são importantes. O contexto das afirmações acima citadas indicam a assimilação entre filosofia e metapsicologia, ao mesmo tempo que a radical separação entre esta e a clínica. A meu ver, é essa separação e aquela assimilação que impedem Marcuse de apreender a radical originalidade da psicanálise. Não apenas a originalidade de seu objeto mas também do seu próprio processo de construção como saber, e, como conseqüência, seu afastamento dos paradigmas constitutivos do pensamento da modernidade. Discutirei, a seguir, essas importantes questões.

Como é sabido, Freud enfatizou diversas vezes o afastamento de seu trabalho teórico da reflexão filosófica. Não parece pertinente atribuir esse posicionamento freudiano nem à sua pretensa ignorância da filosofia nem à adoção, por ele, de um empirismo ingênuo, mas convém atribuí-lo à especificidade de seu objeto, resistente a ser apreendido nas categorias da filosofia dominante. Não surpreende então que ao considerar em sua autobiografia as relações da psicanálise com a filosofia Freud tenha sublinhado a ampla coincidência existente entre aquela e a filosofia de Nietzsche e de 
Schopenhauer, citando em primeiro lugar as coincidências que encontra com o pensamento deste último "o primado da afetividade". Contudo, acrescenta imediatamente que dita coincidência "não pode ser entendida no sentido de uma inspiração da teoria psicanalítica nessa filosofia" (cf. Freud, "Presentación autobiográfica", op. cit., 1976: 55-56)².

Afirmei acima que a autonomia reivindicada por Freud a respeito da filosofia constituiu uma necessidade imposta pela singularidade de seu objeto (o psiquismo inconsciente), e pela especificidade do processo de apreensão desse objeto. Essa especificidade pode ser definida pela prioridade outorgada à clínica - entendida como relação intersubjetiva sustentada na transferência e na vivência da resistência - na hierarquia epistemológica da psicanálise (cf. Birman, 1991). Essa definição da clínica, por sua vez, não deriva de pressupostos teóricos, mas de descobertas realizadas na própria prática clínica. Essa primazia da clínica, contudo, não exclui a construção de um quadro teórico abrangente, representado na obra freudiana pela metapsicologia. Todavia, a necessidade de produzir uma metapsicologia não foi evidente para Freud desde o início de seu trabalho teórico, mas apenas após o fracasso de sua tentativa de sustentar a teoria clínica sobre fundamentos materiais, conforme a concepção ontológica então vigente.

De fato, a construção da teoria psicanalítica foi realizada por Freud em dois registros diferentes e complementares. De um lado, a experiência clínica e a teorização dessa experiência; de outro, a tentativa de inserir esses conhecimentos numa compreensão mais abrangente. Esse segundo registro foi tentando inicialmente pela elaboração de um quadro teórico tributário do materialismo e do positivismo na época dominante. Freud considerava-se um empirista, mas seu empirismo exige uma adequada compreensão. Mais que adesão a uma determinada escola de pensamento, o empirismo freudiano representou uma atitude em relação ao homem, a natureza e aos métodos de investigação; sucintamente uma concepção da ciência como construção conceptual, realizada a partir da descrição de fenômenos e de seu posterior ordenamento e articulação. Entretanto, como afirmamos acima, Freud não era um empirista ingênuo, para quem a

2 Vários anos antes Freud já tinha se ocupado do tema, assinalando a importância que teria "para a ciência e para a vida" a aceitação dos processos anímicos inconscientes. Na mesma oportunidade, assinala a proximidade de seu pensamento com o de Schopenhauer. Cf. Freud, S. "Una dificultad del psicanálisis" (1976: 135). 
percepção seria idêntica ao percebido. A atividade científica - afirma em "Pulsões e destinos de pulsões" - exige desde o início que se apliquem idéias abstratas aos fenômenos que buscam descrever, acrescentando que em um trabalho pioneiro essas idéias devem ser recolhidas de outras regiões do saber (cf. Freud, "Pulsiones y destinos de pulsiones", op. cit., 1976). Entretanto, as bases dos fenômenos psíquicos foram por ele procuradas, inicialmente e conforme a filosofia materialista em que se formara (Plastino, 1993), nos fundamentos em última instância fisiológicos dos fenômenos psíquicos. O esforço mais elaborado para sustentar sobre bases materiais a compreensão dos fenômenos verificados na clínica foi desenvolvido por Freud no fracassado "Projeto de psicologia para neurologistas", no qual intentou compreender "os processos psíquicos como estados quantitativamente comandados de umas partes materiais comprováveis" (cf. Freud, "Proyecto de psicología", op. cit., 1976: 339).

No "Projeto", o objetivo de Freud era, pois, o de encontrar um fundamento para conhecimentos já produzidos na prática clínica, tentando construir sobre bases físicas e biológicas uma teoria geral das neuroses e do próprio funcionamento psíquico. Esse projeto, como é sabido, foi abandonado. $O$ motivo desse fracasso foi a impossibilidade de explicar - sobre essas bases - o fenômeno do recalcamento, "cujo conhecimento clínico fez grandes progressos em outros aspectos" (cf. Freud, "Carta de 8 de outubro de 1895", in A correspondência completa de S. Freud para W. Fliess, 1986 [1887/ 1904]: 142). Como, com efeito, deduzir do jogo das quantidades, fenômenos de ordem emocional que, segundo se constata na clínica, estão na origem dos mecanismos de defesa? Foi pois a questão da qualidade, ou se quer a impossibilidade de reduzir a quantidades fenômenos que são do registro da qualidade, o que determinou o fracasso dessa tentativa. É verdade que, mesmo após ter abandonado a tentativa configurada pelo "Projeto", Freud manterá durante muito tempo a "hipótese de fundo" que sustentava um fundamento em última instância fisiológico dos fenômenos psíquicos. $\mathrm{O}$ abandono final dessa "hipótese de fundo" - isto é, da filiação à tese materialista - só será realizado por Freud no final de sua obra teórica. Assim, em seu "Esboço da psicanálise" afirmará que "se fosse possível estabelecer uma referência precisa sobre o 'cenário' orgânico desses processos [os processos psíquicos] no máximo obteríamos sua localização precisa, sem no entanto progredir na sua compreensão" (cf. Freud, "Esquema del psicanálisis", op. cit., 1976: 143). Essa modificação do pensamento freudiano se insere no contexto de breves porém importantes considerações epistemológicas sobre 
as quais voltarei mais adiante. Entretanto, se ao abandonar o "Projeto" Freud mantém a hipótese de fundo sobre o fundamento em última instância fisiológico dos fenômenos psíquicos, o mesmo não acontece com a tentativa de fazer derivar diretamente os fenômenos psíquicos de forças físicas. Assim, a abordagem da energia psíquica como uma quantidade - que Freud afirma ter se constituído num hábito de pensar - é utilizada no trabalho sobre "O chiste e sua relação com o inconsciente" apenas como uma figuração, uma ilustração para falar do desconhecido (cf. Freud, "El chiste y su relación con lo inconsciente", op. cit., 1976: 140-141). No mesmo sentido, o conceito central de "investidura" possui, já no capítulo VII da "Interpretação dos sonhos" (cf. Freud, "La interpretación de los sueños", op. cit., 1976), um significado estritamente psíquico, alheio à conotação fisicalista que possuía no "Projeto".

A necessidade de produzir uma metapsicologia torna-se evidente, para Freud, a partir de duas constatações. Em primeiro lugar, a já mencionada impossibilidade de deduzir a realidade psíquica da realidade material, já que esta constitui uma forma particular de existência que não deve confundir-se com aquela (Freud, "La interpretación de los sueños", op. cit.: 605). Em segundo, a inexistência nos conhecimentos até então produzidos pela psicologia que servisse de embasamento para as descobertas realizadas por Freud. Não existe "nenhum conhecimento psicológico ao qual fosse possível subordinar - como princípio explicativo - os processos anímicos descobertos através da análise dos sonhos", escreve Freud em "Interpretação dos sonhos" (idem: 506), justificando a introdução do capítulo metapsicológico em sua obra.

Entretanto, a metapsicologia não será construída como o fundamento do saber psicanalítico mas como sua superestrutura especulativa (cf. Freud, "Presentación autobiográfica", op. cit., 1976: 31), pensada por Freud como provisória e em consequiência suscetível de ser modificada quando assim o exigissem novas descobertas clínicas. É, pois, a primazia da clínica que determina o caráter provisório da metapsicologia. Isto porém não significa minimizar a importância da superestrutura teórica, mas evidencia a complexidade e riqueza do processo de formulação de um novo saber, feito de múltiplas articulações. Estas podem então ser descritas como um processo no qual a primazia corresponde à observação clínica - como experiência de relação intersubjetiva -, teorização dessa experiência e construção de hipóteses metapsicológicas, constitutivas de uma superestrutura teórica referida a constelaçōes insuscetíveis de observação direta (idem: 31). Assim, a 
descoberta do narcisismo impôs a superação do primeiro dualismo pulsional, abrindo o caminho para a formulação do segundo.

Assim, ainda, o reconhecimento de resistências inconscientes nos analisandos tornou evidente as insuficiências da primeira tópica, constituindo-se num dos motivos para a formulação da segunda, e também a consideração dos afetos sofrera profundas modificações na evolução da metapsicologia freudiana. Inicialmente reduzidos a quantidades na primeira formulação metapsicológica, eles serão reconhecidos na sua qualidade a partir da segunda teoria pulsional e da doutrina da ambivalência afetiva originária. Essa permanente reformulação da metapsicologia não significa necessariamente - nem regularmente - o abandono dos conceitos anteriormente formulados. Porém impõe a esses conceitos uma ressignificação que modifica seu sentido à luz das novas formulaçōes. É assim como os conceitos "princípio de prazer" e "princípio de realidade" devem ser reinterpretados na ótica da segunda teoria pulsional, segundo indicamos acima, ao invés de reduzir o alcance desta última e fundamental formulação aos limites estreitos daqueles conceitos. Esta parece-me ser uma das principais limitações da interpretação marcusiana do pensamento de Freud.

A acepção da metapsicologia - e seu processo de produção - foi modificada por Freud ao longo de sua obra. Numa primeira acepção, seguindo a trilha indicada em "Pulsōes e destinos de pulsões"3, Freud constrói o registro econômico, o tópico e o dinâmico, considerando que o estudo dos fenômenos psíquicos realizados desde essa tríplice ótica constitui uma abordagem metapsicológica (cf. Freud, "Lo inconsciente", 1976). Posteriormente, contudo, no contexto da profunda virada teórica iniciada com a descoberta do narcisismo Freud avaliará como prematura a segunda síntese metapsicológica, enriquecendo o conceito de metapsicologia, e incorporando nesse conceito a categoria de especulação, isto é, o trabalho da "bruxa metapsicológica" (cf. Freud, "Análisis terminable e interminable", 1976). Com efeito, ao comentar em sua "Apresentação autobiográfica" a tentativa que desenvolvera em 1915 no sentido de elaborar uma metapsicologia, Freud lembra que denominou desse modo as três coordenadas: a dinâmica, a tópica e a econômica. Esse trabalho - continua - teve de ser interrompido, acrescentando que não tinha ainda chegado o tempo para tal formulação teórica (cf. Freud, "Presentación autobiográfica", op. cit.: 55). Esse tempo chegou, como afirma a seguir, com seus últimos trabalhos especulativos.

3 Isto é. tomando empréstimos de outras áreas do saber. 
O papel da intuição nos processos de conhecimento tinha sido sublinhado por Freud desde o início de sua obra. É conhecida sua admiração pelo que denominava "o saber dos poetas":

\begin{abstract}
"Pode-se suspirar pelo saber que é dado a certos homens: recolhem sem trabalho. do turbilhão de seus próprios sentimentos, as intelecções mais profundas as quais os outros, todos nós, temos que abrir caminho através de uma incerteza torturante e de desconcertadas tentativas" ("El malestar en la cultura", op. cit.: 128-129),
\end{abstract}

escreve Freud, comentando um poema de Goethe. A intervenção da "bruxa" metapsicológica, ainda não nomeada, no seu próprio trabalho de elaboração teórica, é sublinhada por Freud desde o início. Assim, ao comunicar a Fliess suas primeiras considerações sobre a significação de Édipo, adverte:

\begin{abstract}
"Sei que se trata apenas de premonições, mas sempre surgiu algo de todas as coisas desse tipo. Outro pressentimento me diz, como se eu já soubesse - embora não saiba absolutamente nada - que desvendarei, dentro de muito pouco tempo, a origem da moralidade" (Freud, "Carta de 31 de maio de 1897", in A correspondência completa de S. Freud para W. Fliess, op. cit.).
\end{abstract}

E ao comentar com o mesmo interlocutor o processo de elaboração da "Interpretação dos sonhos", escreve: "a psicologia vai prosseguindo de maneira estranha: está quase concluída, composta como num sonho e, certamente, com essa forma, nem adequada para publicação, nem feita com esse fim, como mostra o estilo" (Freud, "Carta de 3 de abril de 1898", idem: 319). A participação da "bruxa" na elaboração de sua obra fundacional é enfatizada por Freud ainda ao referir-se ao seu processo de trabalho.

\footnotetext{
"Ele segue - escreve - completamente os ditames do inconsciente, segundo o célebre princípio de Itzig, o viajante dominical: Itzig, para onde você vai? E eu sei? Pergunte ao cavalo. Não iniciei um só parágrafo sabendo onde ele iria terminar. É claro que o livro não foi escrito para o leitor: depois das duas primeiras páginas, desisti de qualquer tentativa de cuidar do estilo. Por outro lado, é claro que acredito nas conclusões. Ainda não tenho a mínima idéia da forma que finalmente assumirá o conteúdo" ("Carta de 7 de julho de 1898", ibidem: 319).
} 
Finalmente, no próprio texto da "Interpretação dos sonhos" Freud apresenta sua descoberta como fruto de um insight (cf. Freud, "La interpretación de los sueños", op. cit.: 27). A opinião de Freud a respeito da participação do inconsciente no processo de conhecimento não é, como se pode constatar nessas citações, nada ambígua. Sobretudo à luz das concepções que teorizará posteriormente, nos textos ditos da "virada dos anos vinte".

A resistência demonstrada pela maior parte do pensamento psicanalítico a aceitar essa participação evidencia, a meu ver, o peso do paradigma moderno e a "naturalizaçāo" do racionalismo - entendido como o monopólio concedido à razão conceptual no processo de conhecimento - operada por esse paradigma. Essa resistência surpreende menos ao se verificar que o próprio Freud precisou percorrer um longo caminho antes de incorporar essa problemática na sua concepção metapsicológica. Com efeito, essa questão tão significativa para a problemática do conhecimento permaneceu, durante muito tempo, na periferia do saber psicanalítico sem ser articulada no corpo metapsicológico. Nesse sentido, teve um destino parecido com o dos afetos. A fundamental significação dos afetos para o psiquismo cedo foi reconhecida, por Freud, em sua prática clínica e em sua teoria clínica. Assim, dizia referindo-se aos "Estudos sobre a histeria" (cf. Freud e Breuer, "Estudios sobre la histería", op. cit., 1976), "estava em vias de obter uma teoria puramente psicológica, na qual atribuía o primeiro lugar aos processos afetivos" (Freud, "Cinco conferencias sobre el psicanálisis", 1976: 15). Também, nesse caso, a descoberta clínica de Freud - isto é, a decisiva significação dos afetos no psiquismo - receberá, no registro da elaboração metapsicológica, uma representação empobrecida, sendo tratada nela apenas como "quantidades". Não é difícil compreender os motivos do empobrecimento das descobertas freudianas quando transpostas para o registro da metapsicologia. Eles derivam do peso de uma ontologia que compreende a Natureza como uma máquina, a separa radicalmente da cultura, desconhece sua dinâmica autopoiética, e a reduz à pura extensão e movimento. Ontologia tanto mais poderosa que se silencia através de sua "naturalização". Paralelamente, introduzir no registro metapsicológico a problemática representada pelo saber dos poetas teria significado reconhecer formas de apreensão do real - de conhecimento, portanto - não mediadas pela razão conceitual em confronto direto com o racionalismo; outro pilar do paradigma moderno.

Assim, a teorização metapsicológica do saber produzido pela psicanálise ficou restringida aos limites estabelecidos pelos pressupostos ontológicos e 
epistemológicos da modernidade. O conhecimento clínico, contudo, continuou avançando, tornando evidente de maneira progressiva a complexidade do inconsciente. Nesse processo, a formulação da segunda síntese metapsicológica tornou manifestos os acertos e impasses da teoria psicanalítica. Os impasses e as novas descobertas levaram por fím à virada dos anos vinte, caracterizada pela formulação da segunda teoria pulsional, e imediatamente seguida pela modificação da tópica, e, logo após, pela segunda teoria da angústia. Com a virada da tópica, Freud teorizou no nível metapsicológico sua maior compreensão da complexidade do Inconsciente, sobre o qual afirmara, já em 1915, que era preciso postular "conhecimentos inconscientes, conexões conceituais, comparações entre objetos diversos" (cf. Freud, "Conferencias de introducción al psicanálisis", 1976). No mesmo ano, no artigo metapsicológico sobre "O Inconsciente", apresenta esse termo como algo vivo, suscetível de desenvolvimento e mantendo com o préconsciente toda uma série de relações, inclusive de cooperação. Acrescenta, ainda, que constituiria um erro imaginar que essas relações se limitam ao recalque, ou que o inconsciente é algo periclitado ou que permanece em repouso (Freud, "Lo Inconsciente", op. cit.: 187). A virada da teoria tópica, sumariamente antecipada em "Mais além do princípio de prazer", e elaborada em "O Ego e o Id", supera então a perspectiva de Inconsciente concebido exclusivamente como uma degradação da consciência, para pensá-lo na perspectiva mais próxima do que Nietzsche denominava uma "potência subversiva" 4 .

Com a segunda teoria da angústia, por sua vez, Freud incorporou finalmente no registro da metapsicologia a significação central dos afetos, atribuindo-lhe, com a inversão de suas relações com o recalque, o papel central na constituição do psiquismo (Freud, "Inhibición, síntoma y angustia", 1976). Mais importante para o tema desse trabalho é ainda a formulação da segunda teoria pulsional, caracterizada pela postulação de duas pulsões elementares, Eros e pulsão de Morte, qualitativamente caracterizadas. A qualidade das pulsões, negada por Freud no início de sua obra, foi se impondo progressivamente a seu pensamento, como esclarece em 1930, referindo-se à sua convicção de que "as pulsões não podiam ser todas da mesma classe" (Freud, "El malestar en la cultura", op. cit.: 114). A incorporação, na segunda teoria pulsional, de pulsões qualitativamente diferenciadas, está intimamente

4 Como é sabido, o conceito de "Id" é tomado por Freud de Groddeck, ele próprio inspirado pelo pensamento de Nietzsche. Cf. Freud, S. "E1 yo y el ello", op. cit., 1976, v. XIX. 
articulada, na reflexão freudiana, com a significação atribuída aos afetos na sua concepção antropológica. Assim, na correspondência com Einstein, Freud afirma ser a segunda teoria pulsional a "transfiguração teórica da universalmente conhecida oposição entre amor e ódio" (Freud, “¿Por qué la guerra?, 1976: 193). Assim, a segunda teoria pulsional exprimia, no registro da metapsicologia, a enorme significaçāo que a ambivalência afetiva originária detinha na teoria clínica.

Com esse conjunto de movimentos teóricos, Freud assumiu as conseqüências de suas próprias descobertas sobre os pressupostos centrais do paradigma moderno; pressupostos que, antes de serem submetidos à crítica, tinham se constituído numa camisa de força que limitava a teorização metapsicológica das descobertas clínicas. Nesse complexo processo, um papel central deve ser atribuído à descoberta, por Freud, da existência da comunicaçāo entre Inconscientes. Essa comunicação é sustentada por Freud como inquestionável no artigo metapsicológico sobre "O Inconsciente" (Freud, "Lo inconsciente", op. cit.: 191), e suposta em questões como as referidas às "neuroses de destino" (Freud, "Más allá del principio de placer", op. cit.: 22). Entretanto, é apenas em 1920, após os impasses da segunda síntese metapsicológica, que Freud articula essa potência do inconsciente na teoria metapsicológica. O faz de diversas maneiras. Em 1920, no texto que inaugura a virada da metapsicologia, sublinha a significação da participação do inconsciente no processo de conhecimento, afirmando sua convicção de que quando se trata das coisas últimas "dos grandes problemas da ciência e da vida, cada qual é dominado por preferências profundamente arraigadas no seu íntimo que, inadvertidamente, são as que atuam quando se especula" (idem: 58). Posteriormente, em 1923, ao elaborar sua segunda teoria tópica afirma que a segunda teoria pulsional resultou do desenvolvimento de uma "intuição", uma "visão" (Freud, "El yo y el ello", op. cit.: 41). Certamente, afirmações dessa natureza não constituíam uma novidade na escrita freudiana, como assinalamos acima, pois já na época da elaboração da "Interpretação dos sonhos" Freud tinha atribuído sua descoberta a um insight. O que constitui uma novidade no período final de sua obra, marcado pela especulação (Freud, "Presentación autobiográfica", op. cit.: 55), é a incorporação da "bruxa metapsicológica", definida por Freud como "um especular, um teorizar metapsicológico, um fantasiar" (Freud, "Análisis terminable e interminable", op. cit:: 228), na epistemologia da psicanálise. A atividade especulativa, como parte do processo de produção do saber psicanalítico, ganha assim, nos textos da virada dos anos vinte, um papel importante. Convém então 
discutir, mesmo que sumariamente ${ }^{5}$, a compreensão freudiana dessa atividade. Ela não parece ter sido compreendida por Freud como uma súbita inspiração, a aquisição intuitiva de uma verdade a partir da qual a teoria podia ser deduzida. Com efeito, ao discorrer em 1932 (Freud, "Mi contacto con Josef Popper-Liynkeus", 1976: 203-204) sobre o processo de produção da "Interpretação dos sonhos", Freud assinala expressamente a decisiva incidência da prática clínica na evolução de sua teoria. Assim, Freud parece oferecer duas versões aparentemente contraditórias sobre a origem de sua obra fundacional. Segundo a primeira, esta seria o resultado de um insight, de acordo com a segunda, fruto de um lento trabalho de acumulação. Essa contradição, contudo, é só aparente. Cada uma das versões privilegia um aspecto de um complexo processo de criação, no qual o lento trabalho de acumulação de experiências e ensaios de explicação teórica prepara o terreno para a emergência do insight. Este, por sua vez, torna possível uma nova compreensão da antiga problemática, ensejando assim a rearticulação e a ressignificação dos conhecimentos precedentes. Também no caso da formulação da segunda teoria pulsional, é preciso lembrar que a experiência clínica sobre o sadismo e o masoquismo (Freud, "El malestar en la cultura", op. cit.: 115) e a experiência clínica sobre a compulsão de repetição (Freud, "Más allá del principio de placer", op. cit.: 57) contribuíram à emergência da "visão" freudiana. Entretanto, como reconhece o próprio Freud, "esse terceiro passo da doutrina das pulsōes não constitui, como os dois anteriores, uma transposição direta da observação para a teoria" (idem). Inicialmente um exercício de curiosidade científica, transformou-se depois numa convicção que adquiriu tal poder sobre Freud que este declara "já não poder pensar de outra maneira" (Freud, "El malestar en la cultura", op. cit.: 115). Assim, nesse complexo processo, o momento que Freud denomina de insight remete a uma questão central à própria descoberta freudiana. Refiro-me ao reconhecimento, por Freud, da capacidade do inconsciente de proceder a operaçōes intelectuais que se realizam sem que a consciência delas tenha conhecimento $^{6}$. Atribuindo ao pensamento inconsciente uma participação

5 Discuto esse tema com maior detalhe em A aventura freudiana: elaboraçāo e desenvolvimento do conceito de Inconsciente em Freud (Plastino, op. cit., 1993).

6 É interessante registrar que Einstein descreve um processo similar ao descrever seu próprio processo de criação teórico. "As palavras e a linguagem, em sua expresão oral e escrita, - escreve -, năo parecem desempenhar papel algum no mecanismo de meu pensamento. As entidades psíquicas que ao parecer servem como elementos de pensamento são certos signos e imagens, mais ou menos claros, que se podem reproduzir e combinar 'voluntariamente'. Existe, claro, alguma relação entre 
fundamental na produção intelectual e artística, Freud cita os exemplos de Goethe e de Helmholtz, afirmando que o essencial e realmente novo nas suas criações "lhes foi dado como um insight e adveio à percepção quase pronto" (Freud, "La interpretación de los sueños", op. cit.: 600601). À mesma problemática pertence a questão da telepatia, preocupação freudiana em geral silenciada pela reflexão psicanalítica, ainda em vida de Freud. Assim, seu artigo "Notas adicionais à interpretação dos sonhos", inicialmente destinado a ser incorporado à obra $A$ interpretação dos sonhos, não o foi devido à forte oposição de Ernest Jones, temeroso de que seu conteúdo prejudicasse a causa da psicanálise nos círculos científicos. Outro trabalho de Freud, "Psicanálise e telepatia", escrito em 1921, só foi publicado em 1941, após sua morte. A problemática da telepatia foi abordada, por Freud, com prudente expectativa e progressiva aceitação. Declarando-se nāo completamente convencido sobre a existência do fenômeno, porém pronto para o convencimento, Freud afirma que através da descoberta do inconsciente a psicanálise preparou o caminho para a aceitação de hipóteses de processos do tipo da telepatia (cf. Freud, "Sueño y ocultismo", 1976: 49).

$\mathrm{Na}$ resistência oposta por boa parte do pensamento psicanalítico às conseqüências do papel central concedido por Freud à especulação na epistemologia da psicanálise, opera certamente a preocupação de sustentar a cientificidade da psicanálise. O próprio Freud não ficou isento dessa preocupação (Freud, "En torno de una cosmovisión", 1976: 146-147). Todavia, é possível que na resistência de Freud às descobertas por ele próprio realizadas tenha atuado também o peso do paradigma científico em que se formara. O acompanhamento da evolução de seu pensamento demonstra essa resistência. Assim, na primeira época de seu trabalho, ao escrever com Brëuer seus "Estudos sobre a histeria", Freud vislumbrou porém rejeitou reiteradamente a existência do Inconsciente (Freud e Breuer, "Estudios sobre

esses elementos e os conceitos lógicos correspondentes. É igualmente claro que o desejo de atingir por fim conceitos logicamente unidos constitui o fundamento emocional deste jogo, bastante indefinido, com os elementos anteriormente mencionados. Porém, tomado desde um ponto de vista psicológico, este jogo combinatório é, ao parecer, a característica principal do pensamento produtjvo. antes que se estabeleça um vínculo qualquer com uma construção lógica em palavras ou outros signos comunicáveis aos demais. Os elementos mencionados precedentemente são, no meu caso, de tipo visual, e em algumas pessoas são musculares. Apenas em uma segunda etapa as palavras ou outros signos convencionais devem ser dificultosamente desenterrados, quando o jogo de associaçōes foi suficientemente estabelecido e se pode reproduzi-lo a vontade". Citado por Laborde-Nottale, E. em La videncia y lo inconsciente (1992: 158-159). 
la histería", op. cit.: 279 e 293). E, posteriormente, após afirmar a sua existência, o pensa inicialmente apenas como um processo especial, para só mais tarde afirmá-lo como uma realidade ontológica. Em todo esse processo a experiência clínica foi demonstrando a Freud a insuficiência de seus pressupostos teóricos, impondo sua reformulação. $O$ acompanhamento do processo de formaçāo do pensamento freudiano demonstra que, junto com as mencionadas resistências, sua reflexāo foi marcada por um intransigente respeito pelo seu objeto e pela firme decisão de não ocultar nem simplificar nada. Nisto reside, a meu ver, um dos traços mais marcantes da genialidade de Freud. Foi essa genialidade e essa coragem que constituíram a psicanálise num saber crítico do paradigma da modernidade.

\section{Um Saber sobre a Alma Humana}

A assimilação realizada por Marcuse entre filosofia e metapsicologia não constitui uma questão que se limite a uma simples diferença de denominação. Como surge das considerações precedentes, cada um desses conceitos veicula perspectivas radicalmente diferentes a respeito da concepção do processo de produção da teoria psicanalítica. Pensando a metapsicologia como uma filosofia e ao mesmo tempo separando-a da experiência clínica, Marcuse ignora a originalidade do processo de produção do saber elaborado por Freud, originalidade imposta pelo seu próprio objeto. Situandose ao interior do paradigma da modernidade, Marcuse pensa a metapsicologia como uma construçāo teórica elaborada dedutivamente a partir de princípios gerais. Como conseqüência, o que em Freud era uma construção auxiliar - e provisória - utilizada para pensar conhecimentos obtidos a partir da prática clínica, transformou-se na reflexão marcusiana em fundamento da própria teoria. Assim, os conceitos "princípio de prazer" e "princípio de realidade", elaborados por Freud para pensar o processo de socialização do sujeito, foram pensados por Marcuse, na ótica materialista, como um limite contingente imposto pela necessidade de reproduzir a vida material, isto é, pela necessidade do trabalho. E a superação da contradição entre esses dois princípios foi pensada - como se viu - no contexto da dialética marxista.

Entretanto a metapsicologia não é uma filosofia nem foi construída, como mostramos, através de um processo dedutivo. Sustentando-se na experiência clínica, Freud construiu uma teoria sobre o psiquismo humano totalmente diferente daquela que pensa o homem como sendo apenas uma 
"máquina de necessidades materiais. Ele elaborou um saber sobre a "alma"7 humana centrada no desamparo, a ambivalência afetiva originária e a insuperável necessidade do outro. $\mathrm{Na}$ concepção freudiana madura é esta ambivalência e esta necessidade - e não apenas a necessidade de inibir o prazer sexual para orientar a libido para o trabalho produtivo - que tornam necessária a emergência da lei. Como se assinalou, o próprio Freud precisou percorrer um longo caminho, feito de décadas de escuta clínica, reflexão teórica e especulação, para poder reconhecer não apenas a originalidade de seu objeto mas também a originalidade do processo de conhecimento desse objeto. Com isto, inscreveu a psicanálise no grande movimento de crítica do paradigma moderno e de elaboração de um novo paradigma. O reconhecimento de afetos originários qualitativamente diferenciados da especulação como parte integrante do processo de conhecimento constitui aspectos centrais dessa transformação paradigmática.

A avaliação da significação do postulado de Freud sobre a ambigüidade afetiva originária deve ser pensada no contexto da radical transformação que o paradigma emergente propõe na compreensão das relações entre natureza e cultura. Assim, constitui um erro desautorizar esse conceito freudiano como expressão de uma concepção determinista centrada na biologia. A significação maior dos afetos originários é a de integrar, na concepção antropológica, os aspectos emocionais censurados pelo racionalismo hegemônico no pensamento da modernidade. A hipótese freudiana não se coloca em contradição com a crítica da ontologia da modernidade - ser como totalmente determinado - mas amplia a abrangência dessa crítica. Com efeito, não é suficiente criticar a concepção do real como representação de uma ordem transcendente à história.

A crítica da perspectiva essencialista significa certamente criticar a concepçāo de qualquer conhecimento como verdadeiro, isto é, como representação da essência do objeto. Porém ela não equivale a declarar a falência de todo conhecimento. Significa, sim, postular uma concepção deste conhecimento como instrumento sempre provisório e necessariamente pluralista, capaz de fornecer informações pertinentes sobre um objeto não mais pensado como simples; isto é, redutível a uma lógica racional, mas como complexo, o que quer dizer atravessado por diversas lógicas não necessariamente isentas de contradição entre elas. Por isso, a crítica da ontologia da

A expresão "alma" utilizada por Freud não possui, obviamente, conotação religiosa. Com ela. Freud postula a existência da realidade psíquica como diferente da realidade material e não redutível a esta. 
modernidade é inseparável da crítica de sua epistemologia. À complexidade do real, revelado pelas ciências e saberes contemporâneos, corresponde a complexidade das faculdades humanas para apreender esse real. A descoberta freudiana do inconsciente e de seus poderes faz parte da descoberta desta segunda complexidade.

Afirmar a inexistência de uma organização racional do real, que se impõe por si mesma à compreensão da racionalidade humana, não é equivalente a afirmar que diante da atividade do conhecimento só existe um caos absolutamente amorfo, desprovido de quaisquer organização própria mas, surpreendentemente, dotada da propriedade de adequar-se a qualquer organização que a teoria the imponha. Assim, a física newtoniana não representa a essência do real físico, mas certamente capta aspectos dele; do contrário não possuiria nenhuma eficiência na manipulaçāo desse mesmo real. Como escreve Castoriadis (1986), nāo é possível pensar o conhecimento em nenhum dos modelos herdados, isto é, nem como sucessão de construtos que refletem uma ordem existente em si, nem como imposição soberana de uma ordem procedente da teoria a um real caótico e amorfo. A concepção da razāo como razão necessária tornou-se representante exclusiva da razão através de uma interpretação consubstancial à ontologia que concebe o ser como ser determinado e em conseqüência redutível à lógica racional de suas determinaçōes.

Por esse caminho o pensamento foi reduzido à Razāo. Por isso, a lógica que corresponde à ontologia determinista da modernidade é a lógica conjuntista-identitária (idem: 259ss). Construída pela atividade humana do pensamento, essa lógica constitui certamente uma dimensão ineliminável do real, porém ela é incapaz de apreendê-lo na sua complexidade. Sendo um constructo, sua justificação não pode mais ser procurada nos seus fundamentos "necessários", mas deve sê-lo na totalidade de suas conseqüências (cf. Souza Santos, 1989). Assim, toda ciência e todo saber se justificam pelo ganho de compreensão que eles tornam possível, sem que seja possível estabelecer hierarquias entre as formas de conhecimento. É interessante assinalar que Freud já possuía essa compreensāo num momento em que essa abordagem epistemológica apenas engatinhava. Assim, referindo-se à sua segunda teoria pulsional, a justificava argüindo com o ganho teórico que ela propiciava (Freud, "El malestar en la cultura", op. cit.: 115). E em seu "Esboço da psicanálise", no capítulo "O ganho teórico", após reiterar que o "real-objetivo" permanecerá para sempre indiscernível, justifica o empreendimento teórico da psicanálise pelo ganho 
de compreensão que ele torna possível (Freud, "Esquema del psicanálisis", op. cit.: 198-199).

As breves considerações que antecedem não pretendem sequer mapear as múltiplas e complexas questões vinculadas ao processo de transformação paradigmática. Seu único objetivo é o de indicar a complexidade desse processo, que não pode limitar-se à crítica do essencialismo e da concepção representacional da linguagem. Na perspectiva do paradigma emergente é preciso renunciar à pretensão de um conhecimento verdadeiro, espelho da essência do real. É preciso contentar-se com um "conhecimento prudente para uma vida decente" (cf. Souza Santos, 1989), construído, sempre como provisório, a partir de uma pluralidade de abordagens. O desamparo humano e a ambigüidade afetiva originária são dados que não é prudente ignorar ao empreender a tentativa de compreender a alma humana. Considerá-los naturais - bloco de natureza na nossa própria organização psíquica, dizia Freud - significa mais superar a concepção da natureza como "máquina" do que postular sua "eternidade". Certamente a concepção da natureza que surge hoje do conjunto de ciências e saberes que integram o paradigma emergente sublinha seu caráter autopoiético, dinamizada por um processo de criação no qual a atividade humana também participa. Mas isso não impede de considerar dados que, como o desamparo, a sociabilidade humana e a afetividade originária, exprimem uma situação que não parece suscetível de modificação num período histórico pensável. No sentido oposto, ignorá-los é mutilar a compreensão de nós mesmos, constituindo assim - no contexto do paradigma emergente - uma imprudência epistemológica.

\section{Considerações Finais}

A incorporação dos "fatores subjetivos" na análise social constitui um acerto de Marcuse. Recorrendo ao instrumental teórico elaborado por Freud, ele tentou apreender, na sua análise do comportamento humano e social, os aspectos inconscientes, ausentes nas perspectivas das teorias revolucionárias centradas na transformação da consciência. Assim, na sua polêmica com o que denominou as correntes neofreudianas, critica corretamente a transferência por esta efetuada na leitura de Freud "do inconsciente para o consciente, dos fatores biológicos para os culturais", advertindo que os vislumbres de Freud mais penetrantes e concretos da estrutura histórica da civilização estão contidos nos conceitos que os revisionistas rejeitam. Quase toda a metapsicologia freudiana, bem como sua tardia teoria das pulsões e sua 
reconstituição da pré-história da humanidade pertencem a esses conceitos (Marcuse, Eros e civilização, op. cit., 1986: 28-29) ${ }^{8}$. Entretanto, como tentei mostrar neste trabalho, ao confinar sua reflexão nos estreitos limites do paradigma da modernidade Marcuse desenvolve uma leitura reducionista da obra freudiana, tornando-se incapaz de apreender a radicalidade de suas descobertas.

Assim, embora sua intuição básica aponte corretamente para a necessidade de privilegiar a ampliação dos espaços de liberdade nas relações sociais, em um sentido geral sua teoria demonstrou ser totalmente inadequada para compreender tanto as transformaçōes da subjetividade contemporânea quanto as da sociedade. O progresso tecnológico, no qual Marcuse depositava a expectativa de liberar os homens da imposição do princípio de realidade, liberando assim o princípio de prazer e alicerçando uma civilização "não-repressiva", teve consequiências completamente diferentes. Comandado pela racionalidade instrumental, no contexto de uma dinâmica econômica presidida pela objetivo do lucro, dito progresso contribuiu a forjar relações sociais marcadas pela despolitização, o medo, a exclusão e a violência. Nesse contexto, as transformações contemporâneas da subjetividade apontam não para um acréscimo da liberdade e da solidariedade, mas para uma expansão da manipulação nas relações sociais e dos comportamentos caracterizados pelo narcisismo e pelo individualismo. O motivo profundo do fracasso da tentativa teórica marcusiana reside, a meu ver, em sua incapacidade para apreender seu objeto (o sujeito e a sociedade) como objeto complexo, incapacidade à que o confina à inserção de seu pensamento nos limites do paradigma da modernidade. Tornando-se incapaz de pensar os aspectos emocionais do homem, Marcuse desconsiderou seu caráter constitutivo da sociabilidade humana, ignorando as causas profundas dos inevitáveis conflitos entre os homens. Como conseqüência, desconsiderou o papel estratégico da luta democrática, pensando-a, na esteira do marxismo clássico, como decorrência da transformação das forças produtivas ${ }^{9}$. Tentei mostrar neste trabalho que essa orientação teórica da reflexão marcusiana resultava de sua incompreensão do significado das descobertas freudianas, incompreensão ao mesmo tempo alicerçada e evidenciada pela sua compreensão da metapsicologia como uma filosofia. Nessa perspectiva, a leitura

\footnotetext{
8 No mesmo sentido o "Epilogo", denominado crítica do revisionismo neofreudiano.

9 Marcuse parece ter percebido o papel estratégico desta questāo no Adendo que escreve em 1966, onde insiste na importância da democracia como expressāo de Eros.
} 
que Marcuse faz da obra freudiana ignora a profunda significação da transformação operada por Freud nos textos ditos da "virada dos anos vinte", transformação que abrange ao mesmo tempo sua concepção epistemológica e antropológica. Em contraste com essa leitura realizada por Marcuse, a elaboração final de Freud assinala na centralidade dos aspectos emocionais a chave para a compreensão do homem e a sociedade. Centrada no desamparo, a ambivalência afetiva originária e o inconsciente originário, a última síntese metapsicológica freudiana permite pensar as fontes profundas dos conflitos, indicando ao mesmo tempo no reconhecimento do Outro - uma necessidade do sujeito e da vida social civilizada - os caminhos da transformação social possível. Ao salientar as fontes profundamente inconscientes dos conflitos humanos Freud situa as possibilidades de progresso na administração democrática desses conflitos, atribuindo à obra de Eros a responsabilidade na luta pela vida e pela civilização. Na perspectiva freudiana, a predominância de Eros é inseparável do reconhecimento do Outro, e a liberdade e sua expansão não é pensável separada da imposição da lei, entendida como limitação do narcisismo.

Marcuse não pôde apreender a complexidade de seu objeto porque, no contexto do racionalismo do paradigma da modernidade, não pôde compreender a complexidade do processo de conhecimento que caracteriza a elaboração madura de Freud. Entretanto, a insistência de seu trabalho teórico na significação do inconsciente e da constituição psíquica do homem, embora tornada infecunda pela sua leitura reducionista, assinala a direção que é preciso imprimir à reflexão contemporânea.

\section{Referências Bibliográficas}

BIRMAN. J. Fantasma. verdade e realidade. In: BIRMAN, J. Psicanálise, oficio impossível?. Rio de Janeiro: Editora Campus, 1991.

CASTORIADIS, C. A instituição imaginária da sociedade. São Paulo: Editora Paz e Terra, 1986, Segunda Parte.

FREUD, S. Obras Completas. Buenos Ayres: Amarrortu Editores, 1976.

. Cartas. In: MASON, J. (Ed.). A correspondência completa de S. Freud para W. Fliess. Rio de Janeiro: Editora Imago, 1986.

. e BREUER. J. Estudios sobre la histería. In: FREUD, S. Obras Completas.

Buenos Ayres: Amarrortu Editores, 1976, v. I. 
LABORDE-NOTTALE, E. La videncia y lo inconsciente. Buenos Ayres: Paidós, 1992. MANNONI, O. Histoire de la jouissance. In: MANNONI, O. Ça n'empêche pas d'exister. Paris: Editions du Seuil, 1977.

MARCUSE, H. Prefácio político. In: MARCUSE. H. Eros e civilização. Rio de Janeiro: Editora Zahar, 1966.

Eros e civilização. 8. ${ }^{2}$ ed. Rio de Janeiro: Editora Guanabara Koogan, 1986.

MARX, K. e ENGELS, F. Teses contra Feuerbach. In: GIANNOTTI, J.A. (Org.). Karl Marx. Tradução de José Arthur Giannotti. São Paulo: Abril Cultural, 1974 [1845], p. 55-59, 413p. (Coleção Os Pensadores, XXXV.)

A ideologia alemã. São Paulo: Editora Grijalbo, 1977.

PLASTINO, C.A. A aventura freudiana: elaboraçāo e desenvolvimento do conceito de inconsciente em Freud. Rio de Janeiro: Editora da UFRJ/Editora Tempo Brasileiro, 1993.

SOUZA SANTOS, B. Introdução a uma ciência pós-moderna. Rio de Janeiro: Editora Graal, 1989. 